\title{
Optics outreach evolves in southern California: OptoBotics begins to link informal to formal curriculum
}

Donn Silberman

Donn M. Silberman, "Optics outreach evolves in southern California: OptoBotics begins to link informal to formal curriculum," Proc. SPIE 9188, Optics Education and Outreach III, 91880E (15 September 2014); doi: $10.1117 / 12.2061268$

EDIE Event: SPIE Optical Engineering + Applications, 2014, San Diego, California, United States 


\title{
Optics outreach evolves in Southern California as OptoBotics ${ }^{\mathrm{sm}}$ begins to link informal to formal curriculum.
}

\author{
Donn M. Silberman \\ PI (Physik Instrumente) L.P., 5420 Trabuco Rd. Ste. 100, Irvine, CA 92620 \\ Optics Institute of Southern California, 14271 Jeffrey Rd. Ste. 240, Irvine, CA 92620
}

\begin{abstract}
For the July 2013 issue of SPIE Professional Magazine, I was invited to and published an article related to this topic. This paper chronicles the progress made since that time and describes our direction towards bringing optics education from the informal programs we have provided for more than 10 years, to incorporating optics and photonics instruction into formal class curriculum. A major educational tool we are using was introduced at this conference two years ago and came to us from Eyest $\mathrm{vzw}_{\mathrm{vw}}$. The Photonics Explorer Kit has been used as a foundation during some OptoBotics courses and it has been provided, a long with a teacher training session, to 10 local high school science teachers in Orange County, CA. The goal of this first phase is to obtain feedback from the teachers as they use the materials in their formal classroom settings and after-school activities; such as science classes and robotics club activities. Results of the teachers' initial feedback will be reviewed and future directions outlined. One clear direction is to understand the changes that will be required to the kits to formally gain acceptance as part of the California state high school science curriculum. Another is to use the Photonics Explorer kits (and other similar tools) to teach students in robotics clubs "how to give their robots eyes."
\end{abstract}

Keywords: OptoBotics, Optics education pipeline, OptoBotics Summer Camps and courses, OptoBotics educational materials and kits.

\section{INTRODUCTION}

During the course of over ten (10) years providing informal optics education outreach programs, we have developed a concept of the Optics Education Pipeline that seeks to engage students all along the educational path. This concept is shown in Figure 1 where we have separated the grade levels into six (6) sections: K-5, 6-8, 9-12, Community College, University and Professional Education. Our OptoBotics methods are primarily being applied to at grades 9-12 (high school), with some tools extending down to grades 6-8 and up to the Community College level. I have prepared and delivered one professional level webinar titled "OPTOBOTICSsm - Precision Motion for the OpticsAge - A look around the Martian Surface" for our UC Irvine Optical Instrument Design program in December 2012. The main reason for focusing on high school students is because we felt that this was the one most important group that we had not provided good programming. This paper will cover our most recent efforts to correct this situation and create a path forward that is scalable to many high schools in Southern California and beyond.

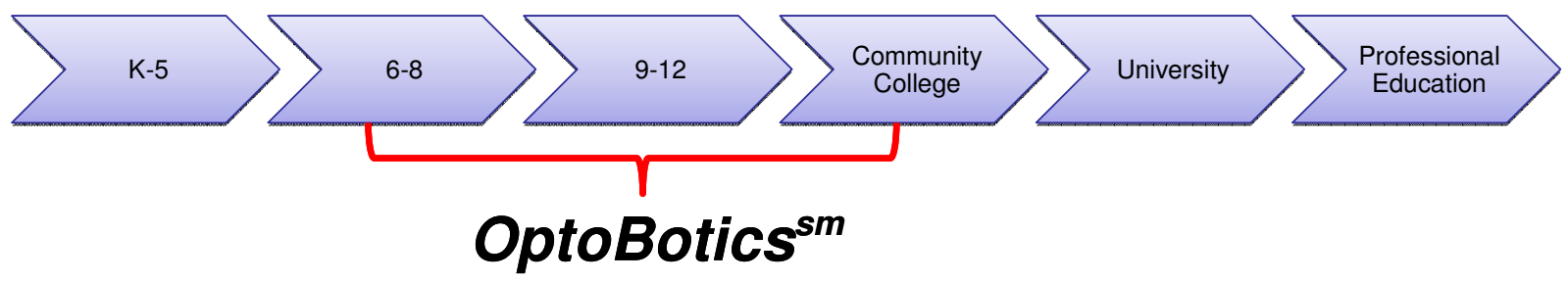

FIG. 1. This Optics education pipeline shows where OptoBotics fits into the progression of optic education outreach.

OPTOBOTICS $^{\mathrm{sm}}$ is a Trademark of OpticsAge and licensed to the OISC for use in its educational programs.

Optics Education and Outreach III, edited by G. Groot Gregory, Proc. of SPIE Vol. 9188,

91880E (c) 2014 SPIE · CCC code: 0277-786X/14/\$18 · doi: 10.1117/12.2061268 


\section{UPDATE FROM 2013 SPIE PROFESSIONAL ARTICLE 1}

Before beginning the update from 2013, I will provide the following framework for this paper starting with a brief summary of my 2013 SPIE Professional Magazine article ${ }^{1}$. In this article, I reviewed how I came to understand the weakness I had when it came to reaching high school students. I was invited to give a guest presentation to the UCLA Summer ArtlSci NanoLab for High School Students in 2007. I brought along a friend (Mark) from JPL with whom I had been working with on a Green Photonics presentation covering Hyper Spectral Imaging for space based remote sensing applications of earth. I did my Optricks Suitcase presentation (targeted at a younger audience) which was not received all that well. My friend did his "Green Photonics" presentation and the hall was all 'a buzz'. Some of the instructors later told me that the students we very excited to learn about this field.

So there my epiphany was born. And I had a path forward in the form of my friend's presentation and that general concept. I started incorporating these concepts into my presentations and things slowly improved. But I still did not know where I was going or how I could get these concepts to many high school students. Then I found Mathobotix just a block away from my Irvine, CA office. I walked in to find some young local college students getting ready to teach some form of STEM and math + robotics. It looked very interesting; but nothing really happened at that point. Then in January 2012, while attending Irvine Valley College's Astounding Inventions competition and exhibition, I saw a young high school student at a robotics club exhibit trying to attach his iPhone to his robot. He was having a tough time because if he had the (expensive) phone on the robot; how could he 'see' what the robot was 'seeing' without having his eyes looking at the iPhone display? At that moment, the word 'OptoBotics' came into my mind and I knew I could help these types of students 'give their robots eyes'. So the vision of what this meant was fairly clear, because we, as professional optical engineers, machine vision engineers, scientists, etc. have been doing these applications for years; but the words we use to describe them to students do not 'click' in their minds. 'OptoBotics' would click. There is a bit more to this story in the SPIE article, but now I will continue with the next topic.

\section{OPTOBOTICS TRADEMARK}

Once I thought that the word 'OptoBotics' would click in the minds of students (and adults), it was important to begin the trademark registration process. This was done with the assistance of another friend and OSSC / SPIE member Mark Gallagher, who also gives SPIE workshops in Intellectual Property with his colleague Lori Yamato. Lori and I worked together to develop the areas of the trademark which are summarized here:

- Model robot kits; robots for personal, educational and hobby use and structural parts...

- Books and magazines in the field of science, technology, engineering, instrument design and robotics; printed instructional, educational, and teaching materials in the field of science, technology, engineering, instrument design and robotics.

- $\quad$ Toy robots; toy robot model kits; toy scale model kit for robots; remote controllable robotic toys; electronic game machines for teaching children

- Educational services, namely, conducting workshops, classes and seminars in the field of science, technology, engineering, instrument design and robotics, and distribution of course materials in connection therewith; organizing and conducting competitions in the field of science, technology, engineering, instrument design and robotics; providing educational information in the fields of science, technology, engineering, instrument design and ......

This trademark process is important to the development of merging informal educational programs and materials with the formal, because there needs to be a substantial sustainable financial component to this effort. Without this element, many of these efforts would be short lived or possibly taken over by others perhaps without the passion to see them through to fruition. This trademark is on track and will be finalized as soon as we finish creating some of the products and materials as described later in this paper.

\section{OPTOBOTICS SUMMER CAMP 2013}

In the spring of 2013, we began planning for our first OptoBotics Summer Camp that would be held at Irvine Valley College's Advanced Technology \& Education Park (IVC - ATEP) in late July. 


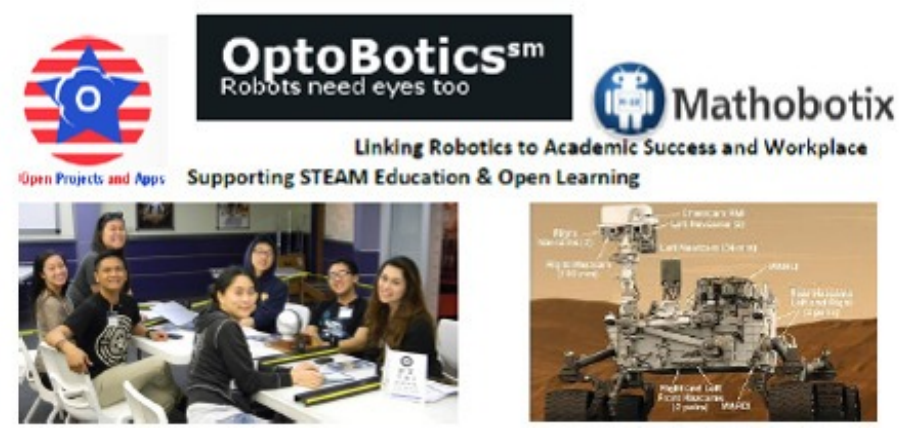

Figure 2. Partial flyer for OptoBotics STEM Summer Camp 2013 for High School Students

For this program, as shown in Figure 2, The Optics Institute of Southern California (OISC) joined with 'Open Projects and Apps' and IVC Community Education to present exciting OptoBotics (optics, lasers \& robotics) based STEM Open Learning Projects in this one fun filled week of summer camp in a special format for High School Students. The students learned the basics of optics and photonics from the Photonics Explorer Kit (more on this later in the paper) and demonstrated their OptoBotics based STEM knowledge and skills in a final presentation / demonstration for their parents on the final day of the camp. For example, some of them added a wireless remotely controlled optical video system to a robotic roving vehicle that lets the owner operator navigate the unit from a different room. They also were able to include a small pointing laser to hit a designated target. An extreme version of this is the famous Mars Rover Curiosity, which was used as a motivational example of what they could do with these technologies. Open Learning projects helped students explore the technology of optics and laser systems with the open source hardware and software (Arduino Controllers and Raspberry Pi), Technical Writing, Design and Modeling, Scientific Research Method, Problem Solving Skills, Learning how to Learn, Presentation Skills, etc., all while having fun! Figures $3 \& 4$ are photos taken during this program.
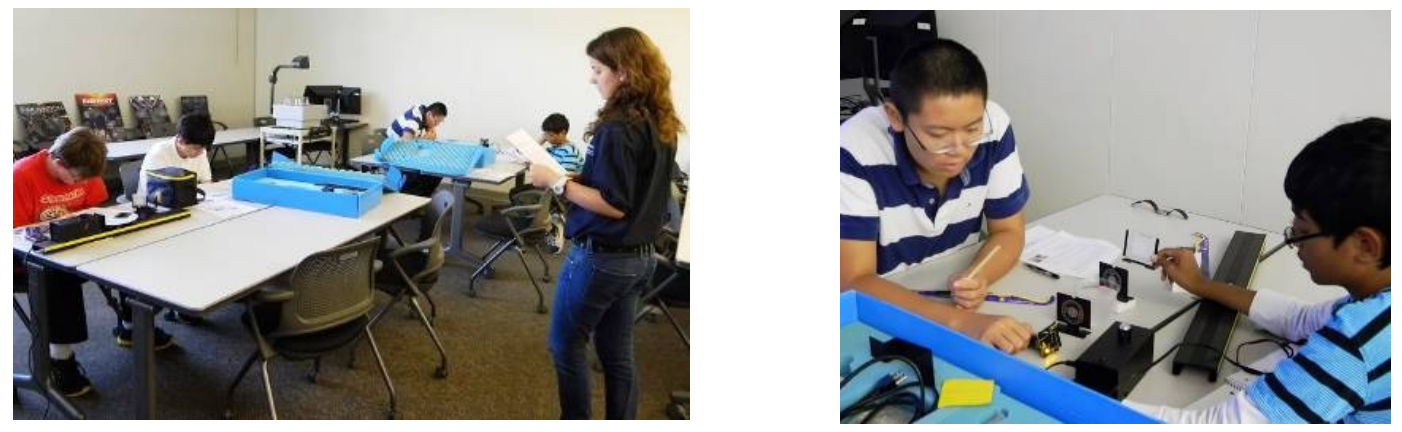

Figure 3. A local college student was trained and worked as a mentor for this camp. OptoBotics Students work with a Pasco Optics Bench and small video cameras.
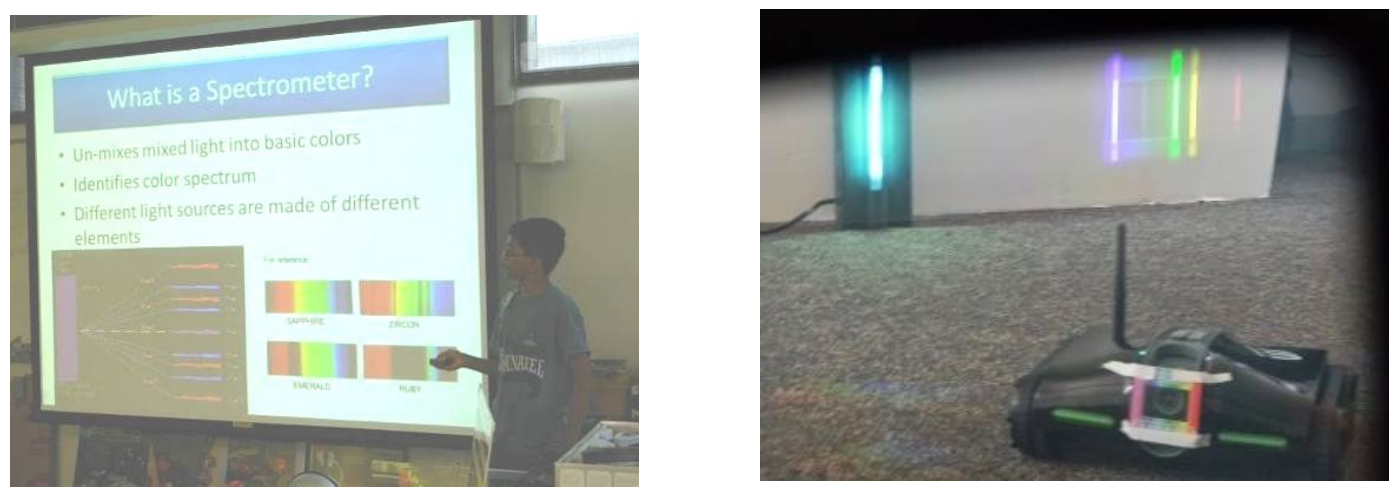

Figure 4. A high school student presents his work using a commercially available Rover 2.0 with a diffraction grating to demonstrate his knowledge of spectroscopy. 
Open Projects and Apps is a local non-profit organization aligned with Mathobotix and focuses on STEM (now STEAMS - Science, Technology, Engineering, Arts, Math and Social Skills.) The Optics Institute of Southern California, formerly a project of Community Partners, is now a Project of Open Projects and Apps; a registered 501(c)3 non-profit organization.

\section{OPTOBOTICS AT SCIENCE FAIRS AND FAMILY DAYS}

Over the past year, we have used our new OptoBotics presentations and demonstrations at a number of Science Fairs and Family day events in Southern California. Starting last August we participated at the Orange County Mini Maker Faire at the UC Irvine Beall Center for Art + Technology and adjacent facilities. Shown here in Figure 5, we had our typical Optricks hands-on demonstrations including Fun with Fresnel and Spinning Your Color Wheels.
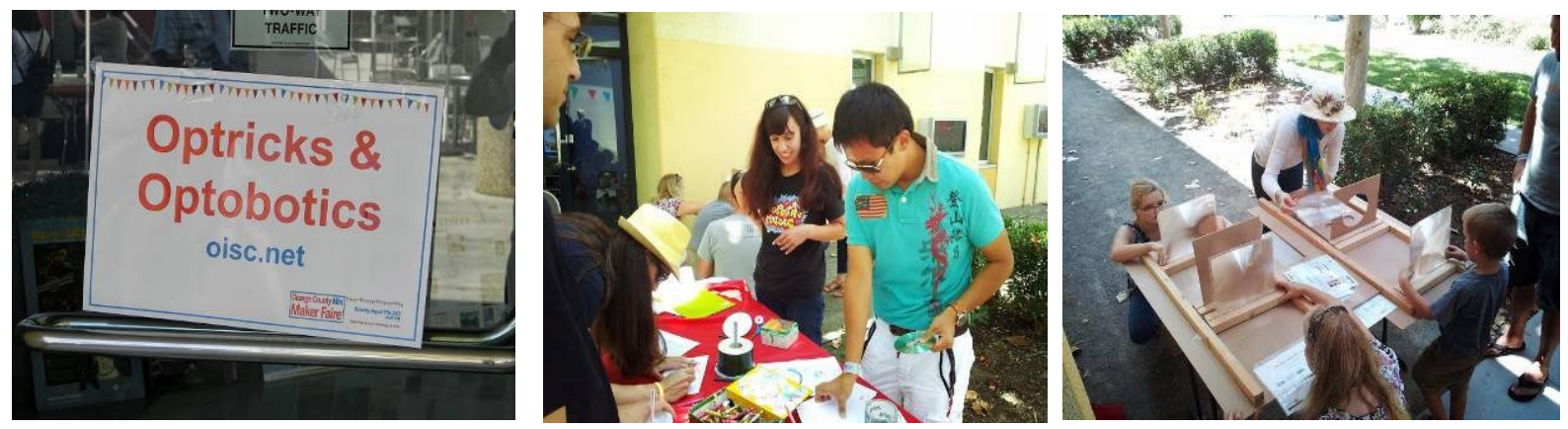

Figure 5. Photos of hands-on Optricks demonstrations at OC MiniMaker Faire in August 2013, including Fun with Fresnel and Spinning Your Color Wheels.

One main concept throughout our ongoing Optics Outreach Evolution is the merging and incorporation of OptoBotics into our Optricks programs. OptoBotics is the next incarnation of our Optricks programs. The photos in Figure 6 show this evolution explicitly where I have given my on stage Optricks presentation, followed directly by the new OptoBotics presentation. This was done during the OC MiniMaker Faire in the Winifred Smith Hall next door to the Beall Center.

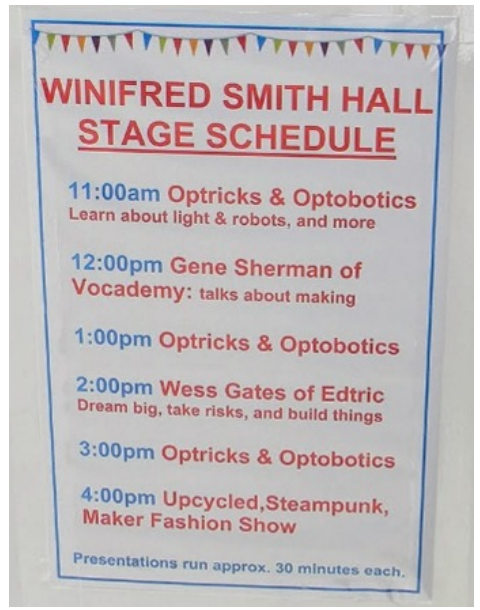

Figure 6. Photos of Optricks and OptoBotics presentations at the Winifred Smith Hall next to the Beall Center during the August 2013 MiniMaker Faire.
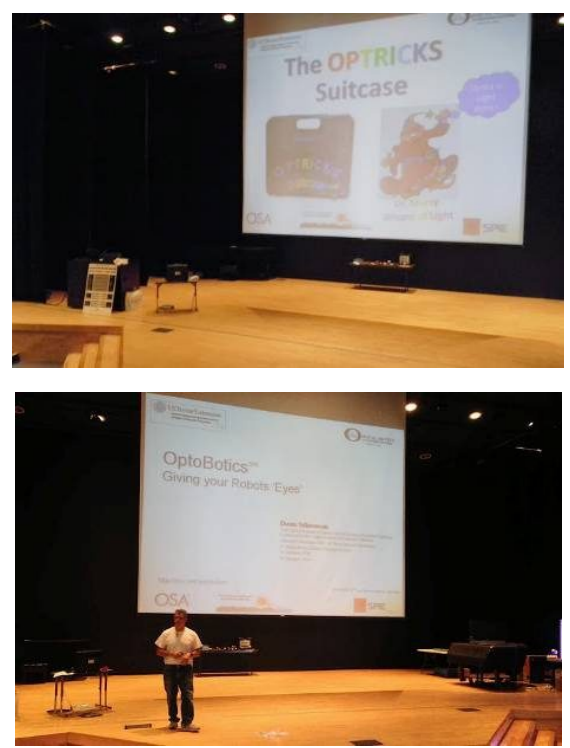

Towards the end of the OptoBotics presentation, I use my wireless AR Drone 2.0 Flying Quadracopter with HD video camera (by Parrot) remotely controlled by my SmartPhone with a tethered cable to the Big Screen TV. This demonstrates the main OptoBotics principle of "Giving Your Robots Eyes" by allowing the audience to see themselves as the flying robot sees them. This key visual experience for the audience is the 'ah-ha' moment that can capture their attention and keep them talking about this technology and encourages them to explore optics and robotics more. 
In November 2013, we continued with the Optricks + OptoBotics merger at the UC Irvine Beall Center for Art + Technology Family Day event. Here, shown in Figures $7 \& 8$, the OISC joined again with the Optical Society of Southern California (OSSC), and the UC Irvine OSA / SPIE Student Chapter for the hands-on demonstrations and presentations.

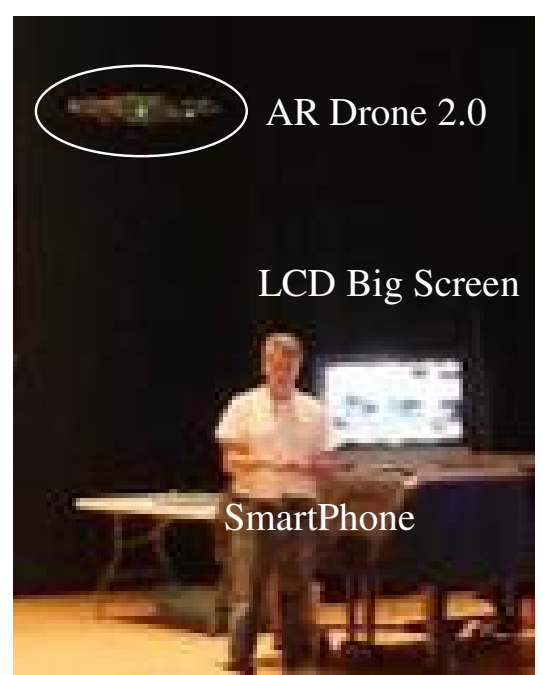

Figure 7. The AR Drone 2.0 with HD video WiFi capability, controlled by a SmartPhone, with the image transferred to a big screen LCD or overhead projector.
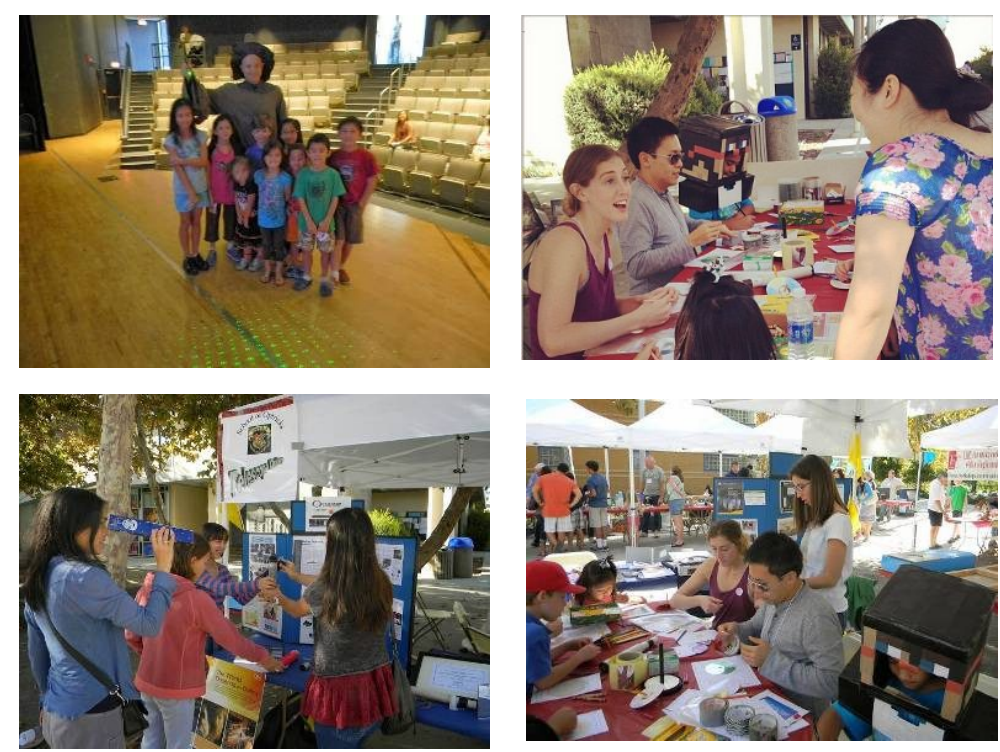

Figure 8. Photos of Optricks and OptoBotics demonstrations at the UC Irvine Beall Center during the November 2013 Family Day Event.

Images of the audience are then captured by the flying HD video camera and the audience sees themselves on the TV or big screen.

Two weeks after the above discussed Family Day event, the OISC, OSSC and UCI Students joined with Open Projects and Apps, Irvine Valley College, Mathobotix and Vital Link OC at the FIRST LEGO League (FLL) Qualifying Tournament in Irvine (located at IVC) to exhibit our Optricks and OptoBotics hands-on demonstrations. Some of our participation is shown in Figure 9. 

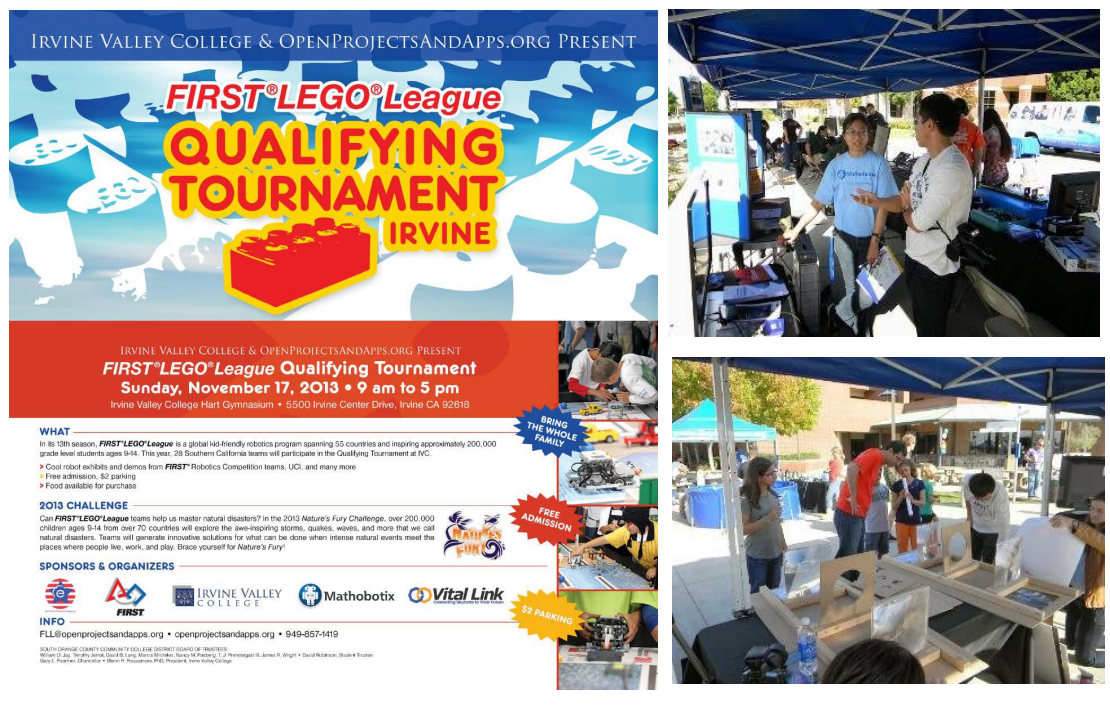

Figure 9. Flyer and photos from FIRST LEGO League Qualifying Tournament hosted by Irvine Valley College and Open Projects \& Apps on November 17, 2013. Photos from top left clockwise show volunteers from Mathobotix and the OSSC, display of SPIE posters in front of live OptoBotics hands-on optics bench, student volunteer Cory Hague, from IVC and Code Orange Robotics Club, Cory's home built Hexacopter with HD wireless video camera (circled in red) streaming live video to a SmartPhone, Tablet or laptop computer, Fun with Fresnel hands-on Optricks demonstration.
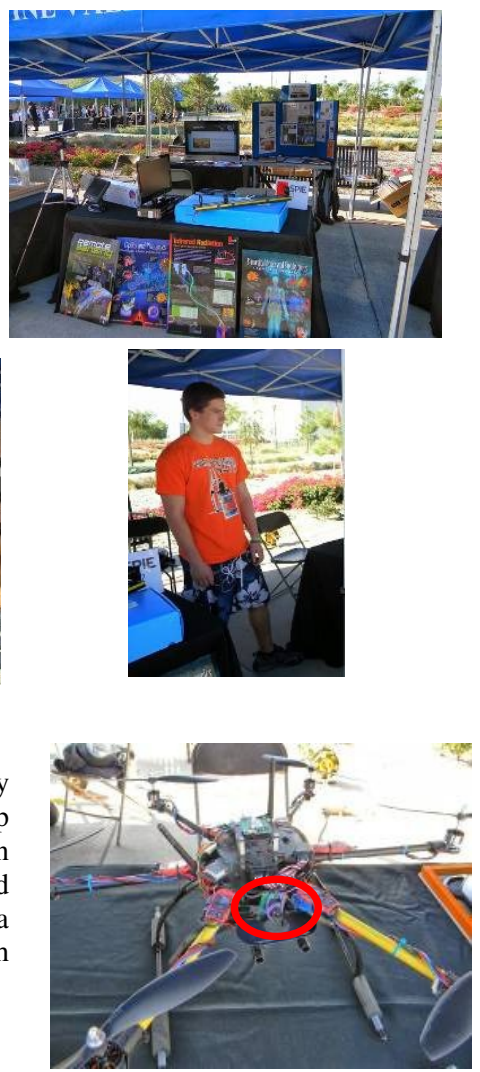

The information shown and described here in this article about this event is limited to the participation of our group and barely captures the essence of the interactions of our volunteers with the attendees. This FLL event was much larger than we can describe in this paper and the reach of the FLL world wide is very large and an introduction and more information can be viewed on their website at: http://www.firstlegoleague.org/. One goal of the OptoBotics outreach endeavor is to leverage the infrastructure of FLL and other robotics programs and add optical components to the mix so students, teachers, mentors, parents and others can gain knowledge and use optics in their student projects and careers.

\section{FIRST FULL OPTOBOTICS COURSE Q1 2014}

At the above described FLL event, we advertised for the first full length OptoBotics course as shown in the partial flyer of Figure 10 (on the next page.) The course description provided that: The Optics Institute of Southern California (OISC) joins with Mathobotix to present an exciting new course: OptoBotics ${ }^{\text {SM }}$ (optics, lasers \& robotics) based STEAMS Open Learning Projects in this fun filled 3 month program in a special format for curious students. In this course, junior high level students will learn how to apply grade level math and science in simulated real world projects. Each project utilizes a sample set of applications of Science, Technology, Engineering, Art, Math and Soft Skills (STEAMS) concepts. Project based learning methods are used in a lab environment. Students demonstrate their finished projects to an audience at the monthly open house.

The class objectives were:

$>$ To have fun playing with light, lenses, lasers, optics, video cameras and friendly computerized systems.

$>$ To learn the basics of using light, laser and optics to give your robots eyes (optical sensors)

$>$ To understand the basics of light by using the Photonics Explorer Kits \& Optics Benches

$>$ To introduce basic problem solving techniques using light, lasers, optics and robots

$>$ To help build soft skills to work in a team environment 
Some Sample Projects included:

Make a product or create a service using their OptoBotics based STEAM knowledge and skills. For example:

$>$ Add a wireless remotely controlled optical video system to a robotic roving vehicle that lets the owner operator navigate the unit from a different room. Include a small pointing laser to hit a designated target.

$>$ Create a spectroscopic optical / video / robotic system to analyze material composition at a distance

Extreme versions of these are on the famous Mars Rover Curiosity.

The students also learned and demonstrated:

$>$ Language and communication skills by writing project reports and presenting their projects to an audience and explain how their program works and how they solved their problems.

$>$ Soft skills included the 5Cs: Critical thinking, Creative problem-solving, Communication, Collaboration, and Cross-cultural relationship building.

$>$ Learning Activities included Hands-on Optics \& Laser Lab, Short Presentations, Writing, Team Review, and Research.

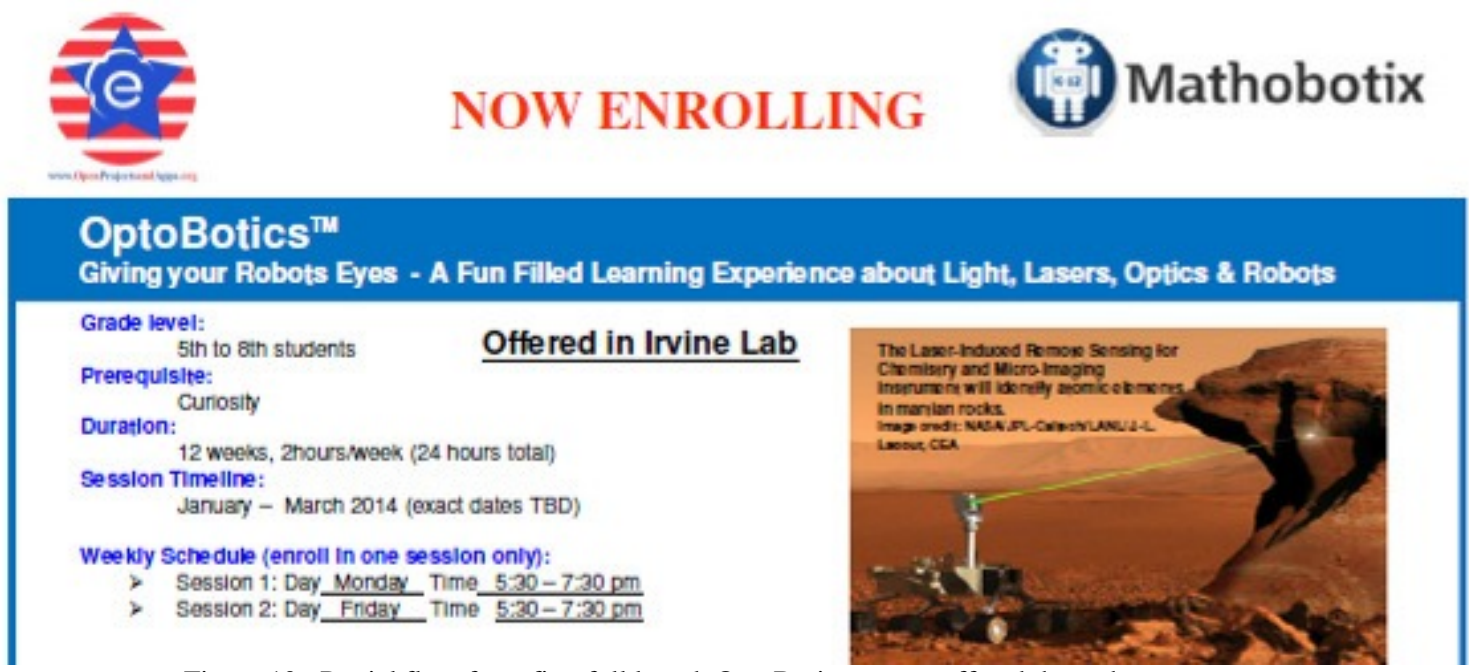

Figure 10. Partial flyer from first full length OptoBotics course offered through

Open Project and Apps at the Mathobotix facility in Irvine, CA

The course began with instructional web based videos about robotic optical systems from big science projects to household systems to orient the students and mentors within the world of optics, photonics, video and vision systems. The amount of exciting high quality instructional material now available on the internet is abundant and provides a very good starting point for classes such as OptoBotics. Then showing the students simple systems like the iRover, Rover 2.0 and AR Drone 2.0 gets them excited about learning more about optics, photonics, lasers, video and how they can incorporate these technologies into their robotic projects.

The course dedicated about $35 \%$ of the time to using various lessons from the Photonics Explorer Kit (more on that kit in the next section) including laser safety, lenses, LEDs, polarizers, diffraction gratings, mirrors and fiber optics. The rest of the time was spent teaching and learning by hands-on experiences how to integrate all the optics and robotics components with the electronics and software to make the OptoBotics systems function according to the designs.

Games were created to enhance the fun and learning experiences including "Hit the Target" with mirrors and lasers, Fiber Optic coded communication challenge, and the final Rover Laser Tag; where the iRovers were equipped with detectors and a laser pointer (and LED) so that when one iRover from one team had its laser hit a detector on another 
team's iRover, the LED would turn on indicating a hit. This was the final game / presentation the students showed their parents and other audience members on the final day of the course.
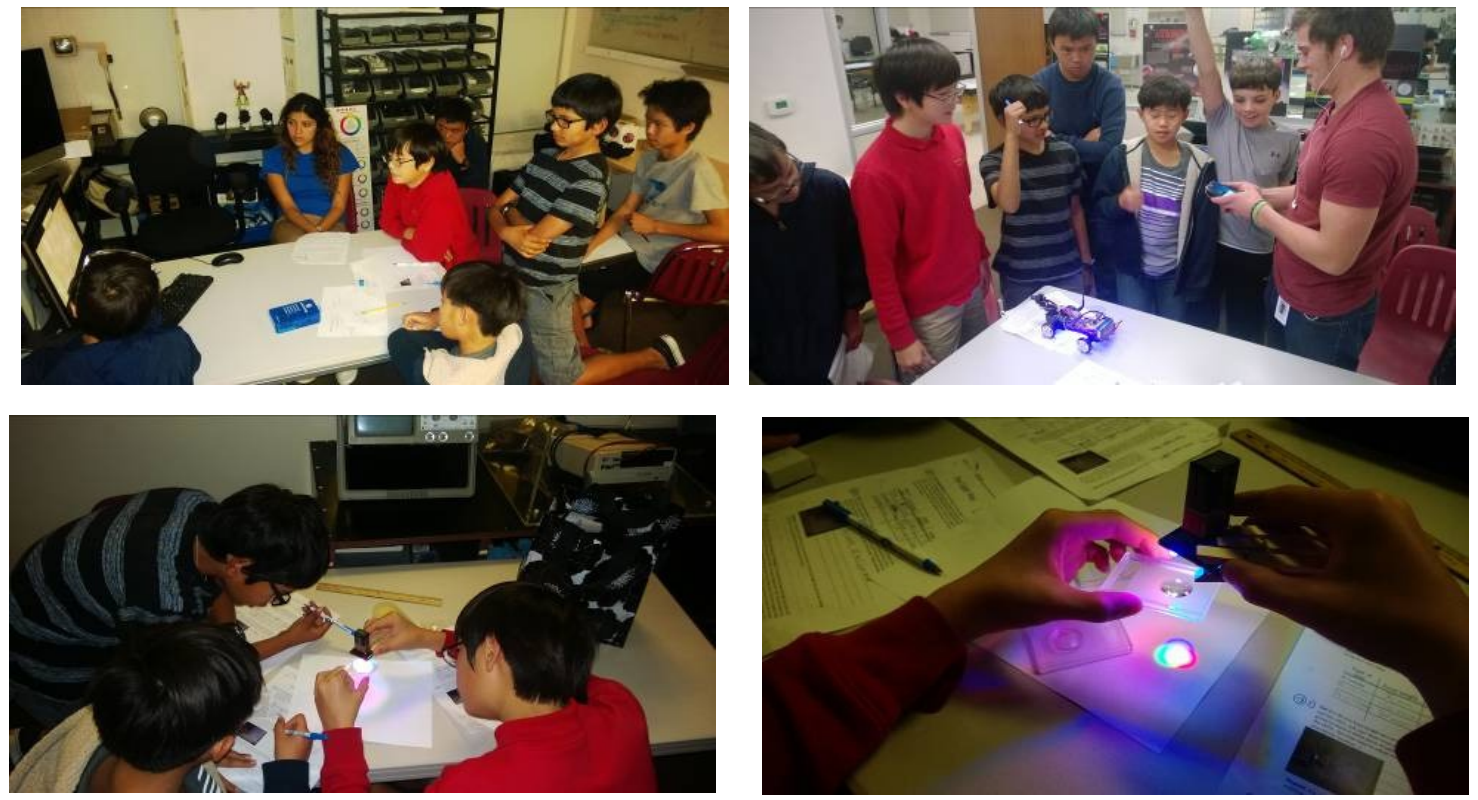

Figure 11. Photographs from first full length OptoBotics course offered through Open Project and Apps at the Mathobotix facility in Irvine, CA. From top left, counter clockwise; students and mentor watching instructor provided internet based course material; mentor demonstrating SmartPhone / WiFi controlled customized iRover with HD video camera, and students using Photonics Explorer kit components during academic portions of the course.

In addition to the Photonics Explorer kits, students were able to use some Pasco Optics Bench kits on loan from Irvine Valley College. This is shown in Figure 12 where a student and mentor are seen programming a Raspberry Pi camera to demonstrate focused red light filtered through a set of parallel slits. This experience was invaluable as a precursor to support projects later in the course that would use the Arduino software and hardware as part of the iRover Laser Tag game development.
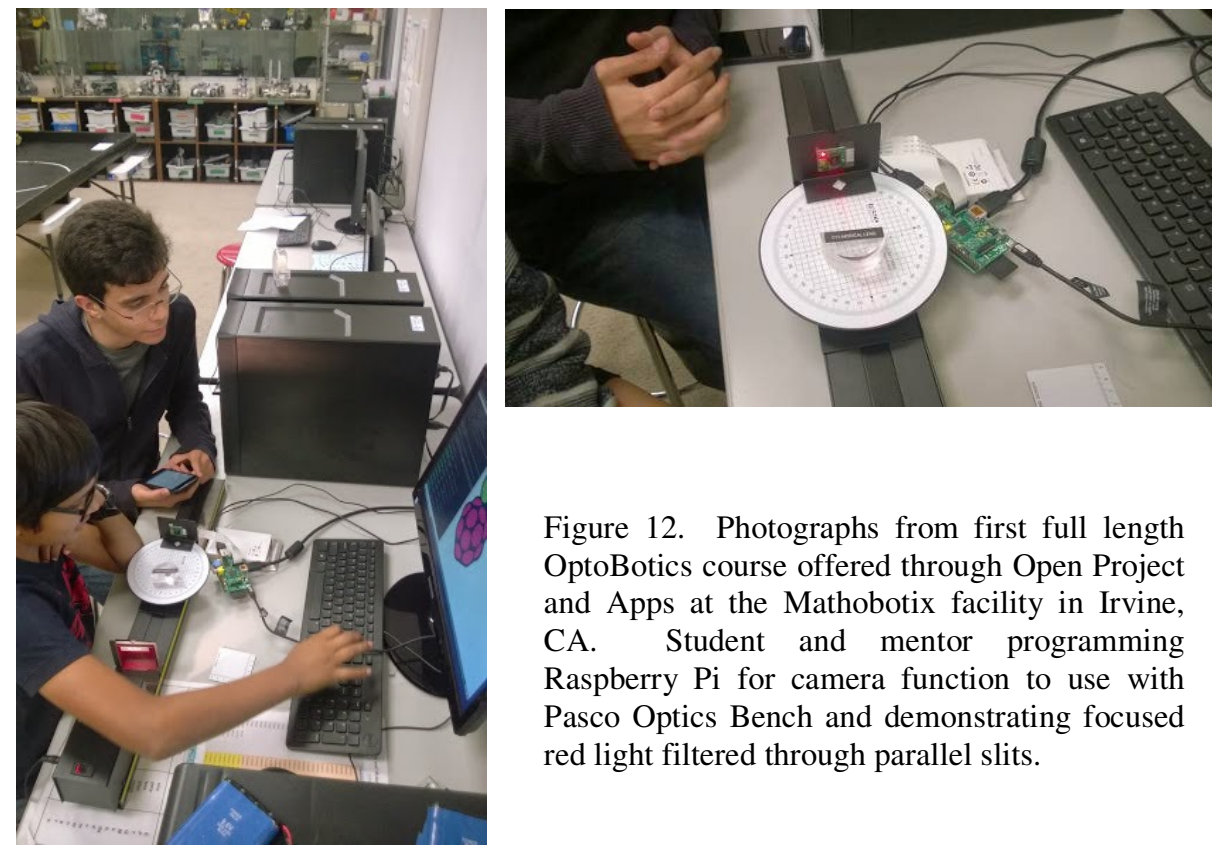

Figure 12. Photographs from first full length OptoBotics course offered through Open Project and Apps at the Mathobotix facility in Irvine, CA. Student and mentor programming Raspberry Pi for camera function to use with Pasco Optics Bench and demonstrating focused red light filtered through parallel slits.

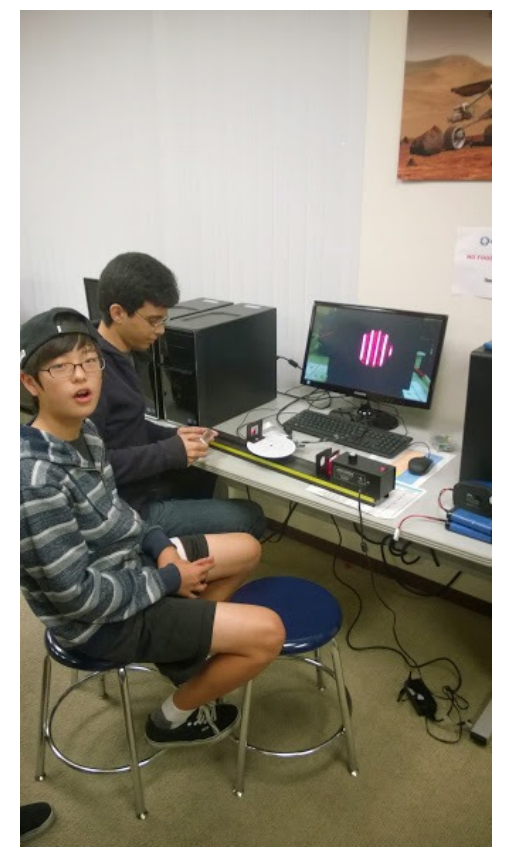




\section{PHOTONICS EXPLORER KITS AND TEACHER FEEDBACK}

Two years ago at this conference, we were fortunate to have Amrita Prasad from Eyest $t_{\mathrm{vzw}}$ present a paper ${ }^{2}$ on their success with their Photonics Explorer Kits. At that time we discussed how we might bring some of these kits to Southern California and by the following Photonics West conference (Feb 2013), a colleague brought one kit to us for demonstration and fundraising purposes. During the months that followed, we demonstrated and promoted the kits at OSSC meetings and other outreach events. We received donations from 10 OSSC Corporate members and arranged to work with Vital Link of Orange County to recruit 10 local high school science teachers to train and provide the kits for their classrooms. By the end of 2013, we had the kits, the science teachers, the time, date and location for our training workshop and we were ready to go. We had the workshop on Jan. 25, 2014 at Precision Optical in Costa Mesa with Brian Monacelli leading the technical review of all the material in the kits and additional materials to put it all in application context.

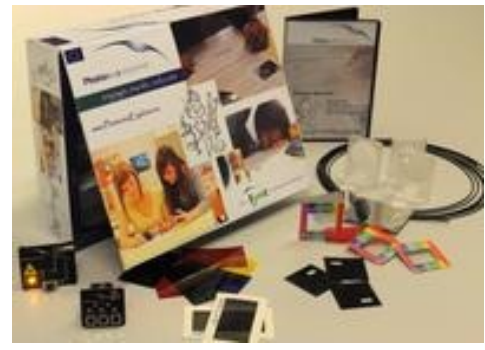

Figure13. Photonics Explorer Kit from Eyest ${ }_{\mathrm{vzw}}$

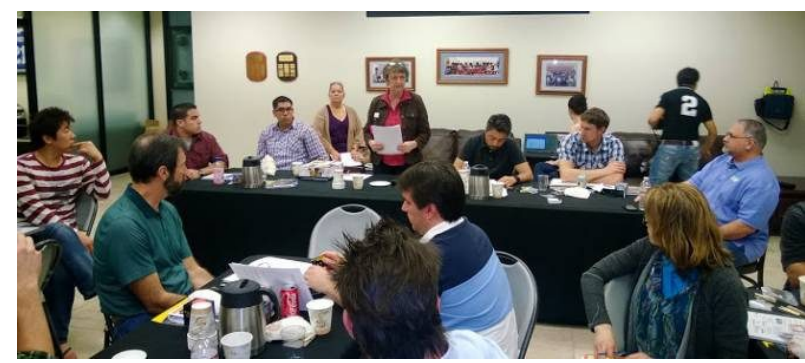

Figure14. Kathy Johnson, Vital Link OC President, welcomes teachers and optics professional volunteers.

Many of these teachers have science, engineering and / or robotics clubs they advise at their schools, so additional notes and materials were provided to encourage merging optics and robotics. This is the direction we will be going and this will be addressed later in this paper.
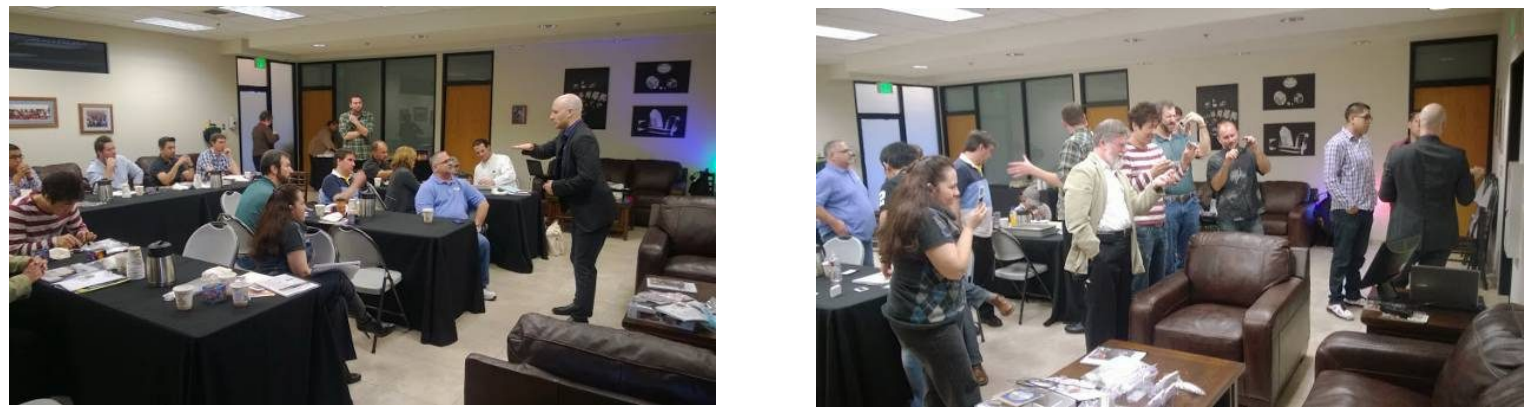

Figure 15. Dr. Brian Monacelli leads the technical review of the Photonics Explorer kits and supplemental materials. Teachers experience hand-on optics experiments assisted by volunteer optics professionals. Nicolaus Lambert, VP Engineering, Precision Optical, hosts the workshop.

The next steps for our work with the Photonics Explorer kits are:

1. Follow up with teachers \& volunteers (Feedback was not yet available as of the writing of this paper.) ${ }^{\mathrm{A}}$

2. Collect more funds for more kits (50 kits $\mathrm{x} \$ 300$ each)

3. Recruit more teachers \& volunteers

4. Repeat training in 2 or 3 sections of $10-15$ teachers

5. Determine how to integrate optics, photonics and OptoBotics into formal classroom curriculum.

\section{SPRING 2014 PROGRAMS}

Following from our successful Photonics Explorer workshop arranged by our friends at Vital Link Orange County, we began working with them by developing and providing a small easy to use Optics Career exhibit based on our "What is 
Light?" demonstration, shown in Figure 16, for their ongoing outreach programs at local high schools and middle schools.
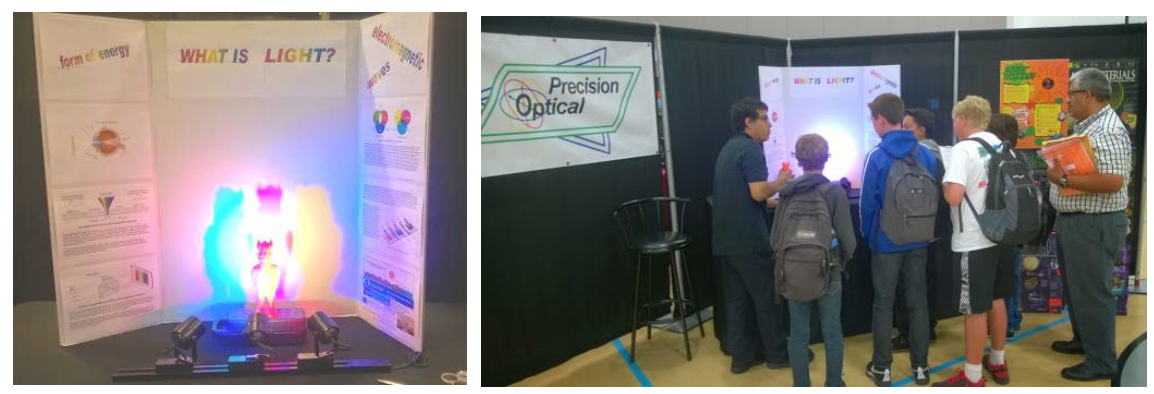

Figure 16. New "What is Light?" exhibit donated by the OISC to Vital Link OC for their ongoing Career Outreach programs to local schools. Precision Optical donated a banner and some optical components for hands-on enhancement. SPIE educational posters complete the exhibit with details the students can enjoy and staff can use as guidance.

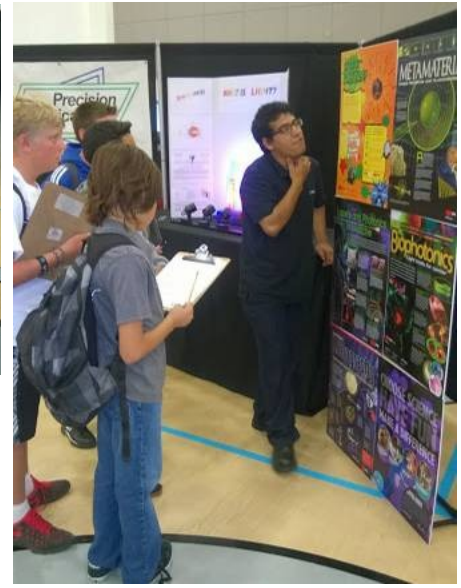

Our friends from Precision Optical also donated a banner and some surplus optical elements to enhance the experience the students have at the booth and provide an easy to remember name.

While OISC volunteers attended a number of the events in March and April, in the list shown in Figure 17, by May, the above described exhibit was fully developed and the Vital Link staff was trained to interact effectively with the students. This now allows the Vital Link staff to carry on reaching out to high school and middle school students, teachers and administrators with our optics outreach exhibits. We can then provide (business) cards with website addresses for students and teachers to reach back to the OISC and optics community for further information and outreach opportunities.

Figure17. Vital Link OC Spring 2014 calendar of career day outreach exhibits. http://www.vitallinkoc.org/

\begin{tabular}{|c|c|c|}
\hline March & & \\
\hline $3 / 7$ & Fri & Fontana HS Exhibit Day \\
\hline $3 / 20$ & Thurs & Laguna Hills HS Exhibit Day \\
\hline $3 / 27$ & Thurs & Buena Park JHS Exhibit Day \\
\hline \multicolumn{3}{|l|}{ April } \\
\hline $\begin{array}{l}4 / 11- \\
13 / 2013\end{array}$ & Fri-Sun & $\begin{array}{l}\text { STEM and the Arts Career } \\
\text { Showcase }\end{array}$ \\
\hline $4 / 23$ & Wed & Talbert MS Exhibit Day \\
\hline $4 / 24$ & Thur & Los Alisos MS Exhibit Day \\
\hline \multicolumn{3}{|l|}{ May } \\
\hline $5 / 16$ & Fri & Alder MS Exhibit Day \\
\hline $5 / 20$ & Tues & Irvine Int. Exhibit Day \\
\hline $5 / 22$ & Thur & Utt Middle School Exhibits \\
\hline $5 / 28$ & wed & Brea Olinda HS Exhibits \\
\hline
\end{tabular}

\section{THE FUTURE OF OPTOBOTICS}

Since the beginning epiphany that sparked OptoBotics into being, it was clear there were many career opportunities that students could pursue that would include optics and robotics. These career opportunities already exist; it is just that the students and most of their teachers, councilors and administrators are not aware of them. So it is one role of OptoBotics to make them aware. The preceding 8 sections of this paper describe programs we have initiated; but clearly this is only the beginning. One of our college mentors, Cory Hague, seen in Figures 9 and 11, has continued helping us see and build the OptoBotics future. Part of the future has an OptoBotics Rover as seen below in Figure 18. Here we 'hacked' an ATV Quad designed to have a young person riding, and added a computer and multiple HD video cameras in an effort 
to allow young people at our outreach events experience something like a Mars Rover. Here you can see a young girl standing in front of the OptoBotics Rover where one camera provides a close up image of the piece of candy she is holding in her hands and a second camera (image on the smaller screen) has a wider field of view.
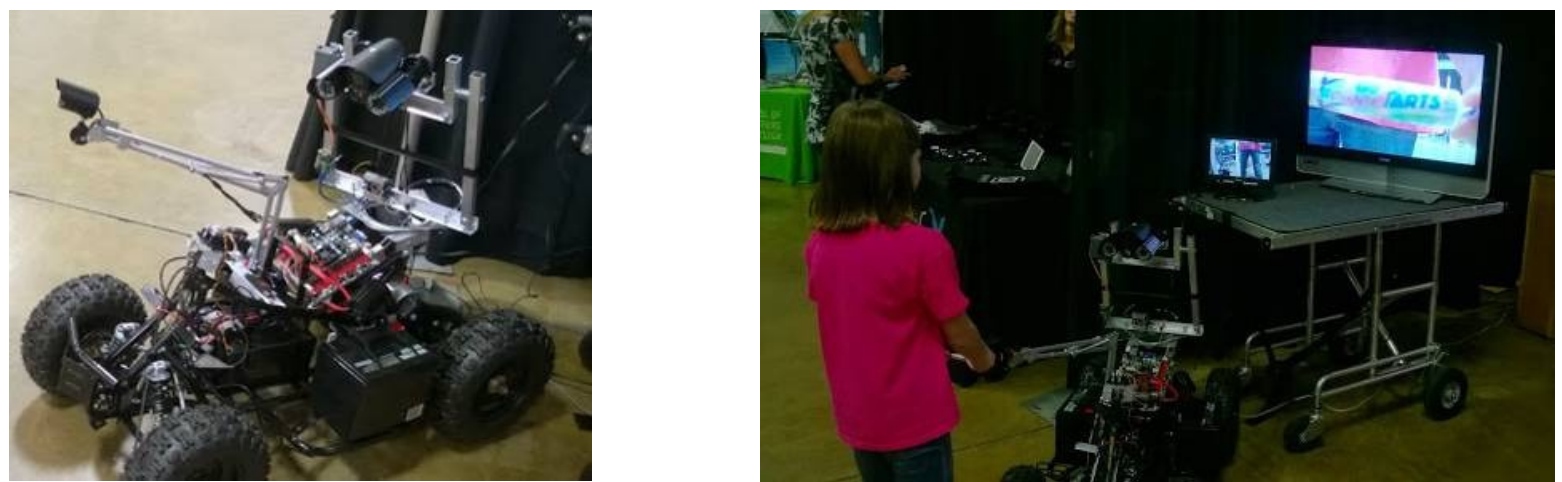

Figure18. OptoBotics Rover at the April STEM and the Arts Career Showcase showing a young girl observing two different images, one of her candy and one wider field of view.

The vision for the future of OptoBotics includes the following list of materials:

- Optricks / OptoBotics Theme Packets

- Optricks / OptoBotics Suitcases for demonstrations

- $\quad$ Photonics Explorer (OptoBotics) Classroom Kits

- OptoBotics video systems for robots

- OptoBotics spectroscopy systems for robots

- OptoBotics polarization systems for robots

- Curriculum and instructions for all the above

- Magazine articles - How to do add optics to your robots

- OptoBotics games \& toys

- OptoBotics competition rules for the robotic educational field

- $\quad$ Dedicated magazine - on-line \& print to OptoBotics

- T-shirts, mouse pads, coffee cups, etc

- After-school programs, presentations, exhibits, science fair concepts

The very early development of some of these has begun and you can see examples in the following figures. Much of it is based on the concept of merging our Optricks materials into OptoBotics.
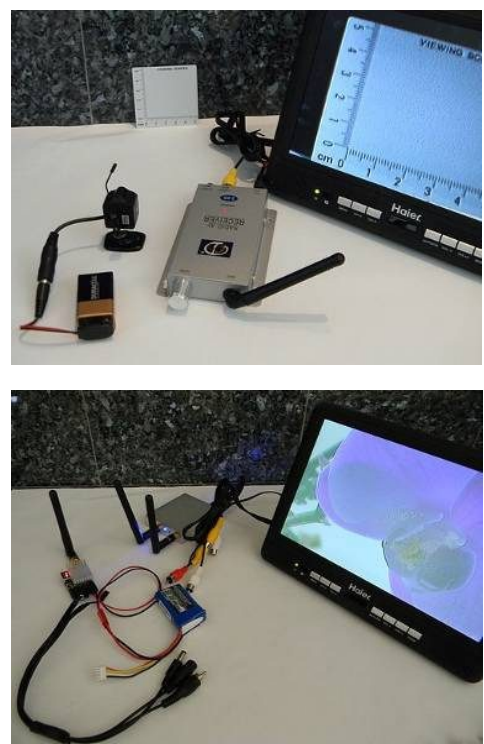

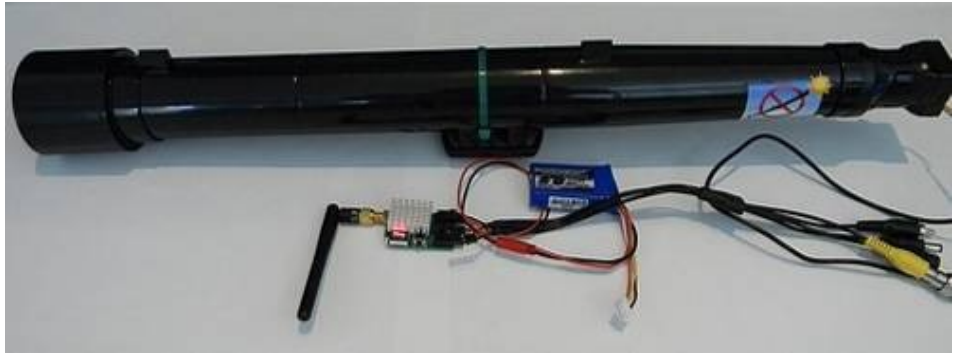

Figure19. Preliminary OptoBotics wireless video systems. Top left photo shows a $2.4 \mathrm{GHz}$ transmitter / Camera driven by a standard 9 $\mathrm{V}$ battery viewing a white target screen with rulings. The bottom left photo shows a $5.8 \mathrm{GHz}$ wireless transmitter / receiver with the image (of a flower) taken through the Galileoscope in the top right photo. 
The above preliminary concept OptoBotics wireless video systems are assembled from purchased components including the Galileoscope. There are a number of on-line stores that sell the components for these wireless video systems; however, much of the knowledge to make them function is left to the hobbyist. One goal of the OptoBotics materials is to provide the next level systems and documentation to offer students and others the information and components to assemble and use OptoBotics kits in a timely and somewhat frustration free manner.

The next more important level for more advanced students includes spectroscopy and polarization concepts and tools for more advanced applications. This is really where the projects get more interesting. Some preliminary concepts for these applications are shown in Figures 20 and 21.
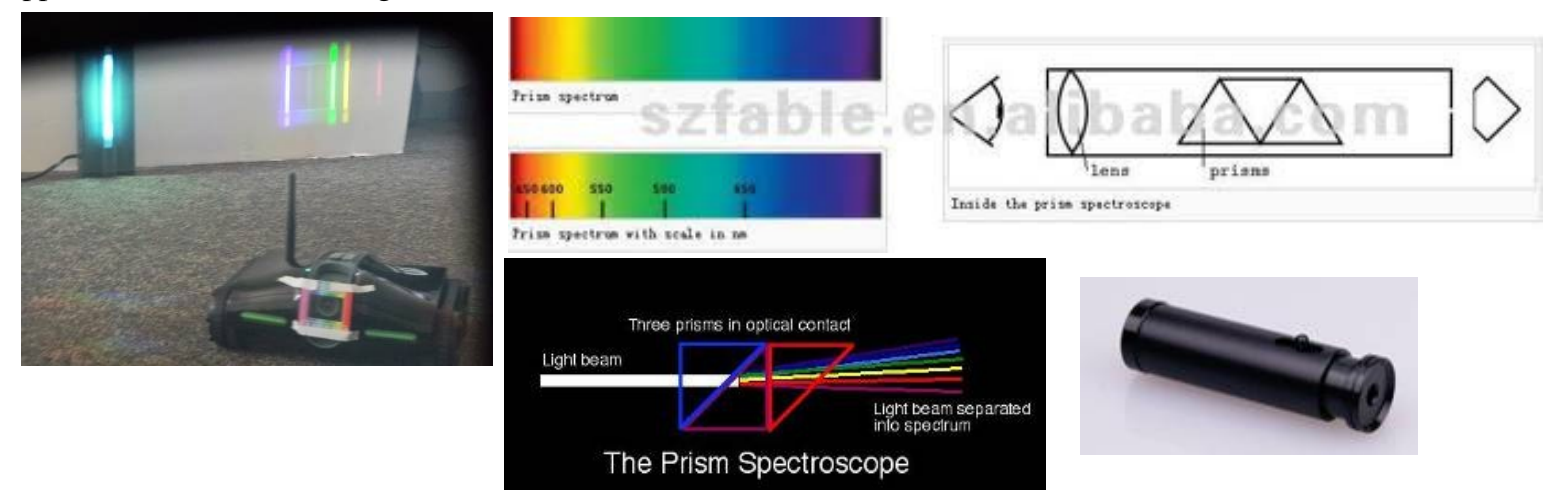

Figure 20. Rover 2.0 with a simple diffraction grating taped over the HD WiFi camera. When aimed at a simple rare gas tube, the wellknown spectrum is captured and can be analyzed. More advanced systems could incorporate standard low cost prism spectroscopes.

\section{Polarized Tree}

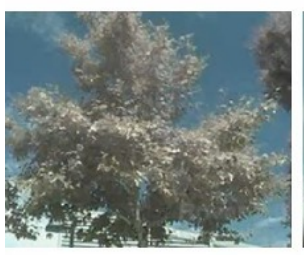

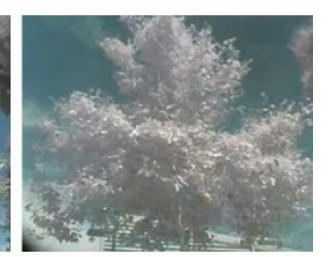

One of our summer camp students took the two images in Figure 21 using the same Rover 2.0 with a standard linear polarizing filter in perpendicular orientations. This demonstrates the use and understanding of polarization in OptoBotics systems. A mentor built a simple motorized rotation mechanism to rotate a simple polarizing filter at any rate of rotation desired (within the capability of the motor.)

Figure21. Two images, shown here, of a tree were taken by an OptoBotics Summer Camp student. He used the Rover 2.0 and a linear polarization filter in perpendicular orientations showing the polarization effects.

A list of some advanced "OptoBotics" applications that students could learn about as career interests include the following complied from the website of Arcturus-UAV.com:

- Intelligence, surveillance, and reconnaissance (ISR)

- Chemical and radiation detection

- Communication repeater node

- $\quad$ Sensor and other payload testing platform

- Area mapping - erosion \& environmental monitoring

- Agricultural, farming \& commercial fishing management

- $\quad$ Fire \& damage assessment

- Border, harbor, \& and canal security

- Convoy, road \& population protection

- Natural resource \& wildlife management

- $\quad$ Pipeline monitoring $\bullet$ power line inspection

- Fire fighting observation and infrared heat detection

- Weather mapping and measurement

- High-altitude, high endurance (HALE) applications

- Releasable, intelligent wing-mounted payload applications

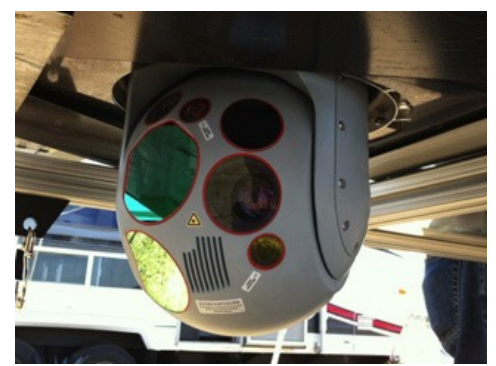

Figure22. Professional imaging systems with multiple vision components for different sensing applications are shown here. Arcturus-UAV.com 
Currently, there exits a world wide amateur drone / UAV community promoted in part by 3D Robotics, who design, develop and sell complete ready to use systems and components for DIY hobbyists, and their on-line DIYDrones.com website; seen here in Figure 23.
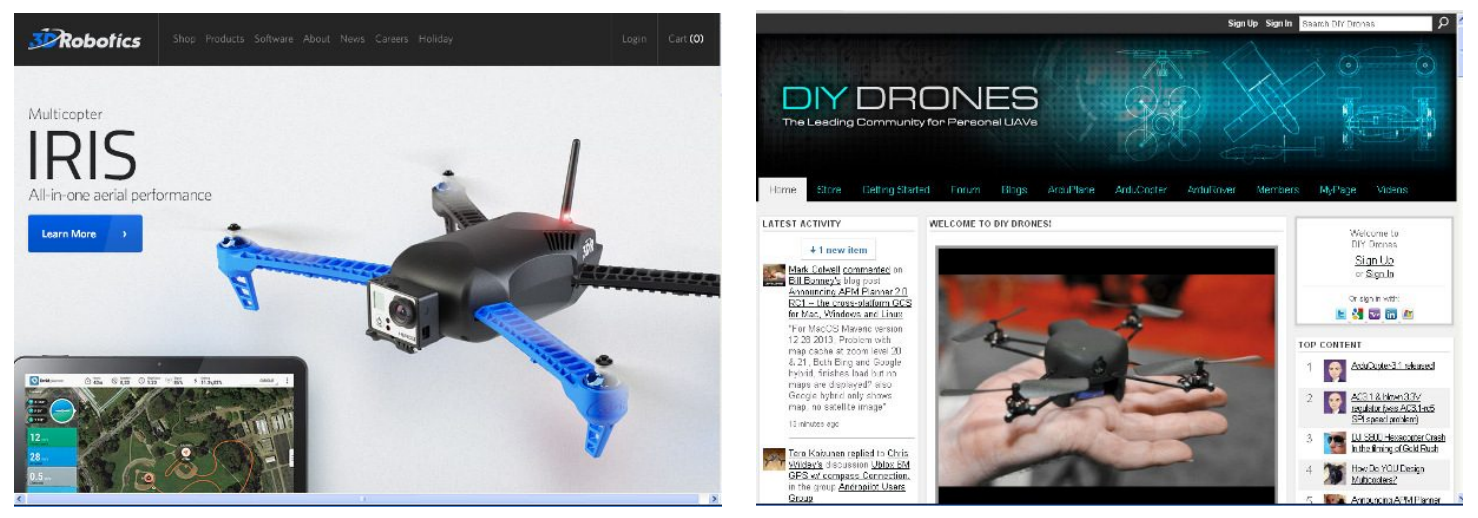

Figure23. Websites for 3D Robotics and DIYDrones.com promote and support the amateur drones and UAV community.

One goal for the future of OptoBotics is develop a similar business model that uses both for-profit and non-profit entities to sustain an ongoing community combining optics and robotics technologies for educational and amateur hobby enthusiasts. The new OISC website has been developed to support such collaboration among people interested in optics education in Southern California and beyond. It is based on the Grou.ps website engine and caters to organizations that have various groups interacting with each other. Figure 24 shows a screen shot of the OISC webpage displaying the various groups such as Careers, Optics Volunteers, OptoBotics, OSA / SPIE Student Chapters, Parents, Teachers, Students and Photonics Explorer Kits.
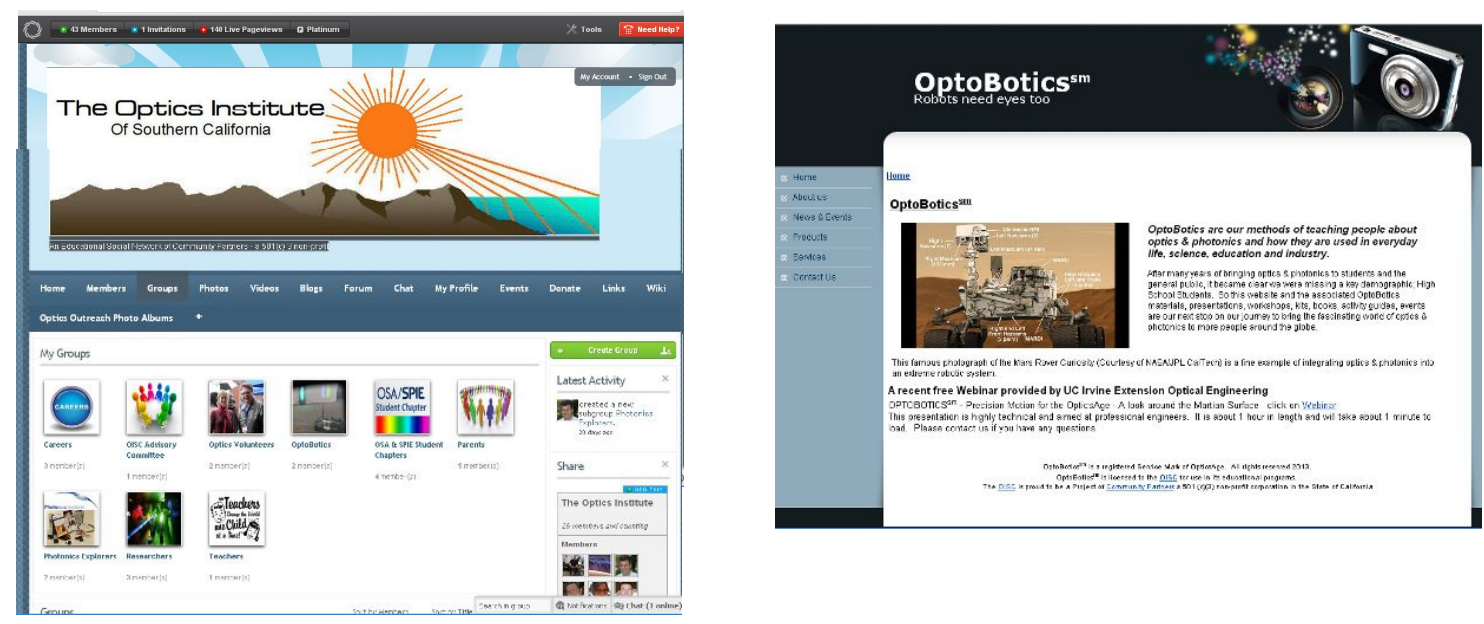

Figure 24. Websites for the OISC and OptoBotics promote and support the optics outreach community.

The OptoBotics website is dedicated to all things OptoBotics and includes information about the concept, history, news, events, products and services. This website will grow as the next steps are completed.

The next most important step is then to develop the OptoBotics materials describe earlier so they can be used by students, teachers, presenters, hobbyists, robotic clubs and others interested in developing their knowledge for fun and careers and we step forward and bring more people in to the OpticsAge. As these next steps are completed, they will 
include information, materials, products and services that will move us from just providing informal education to ways of using these new materials in the formal classroom settings. Once we have these materials developed, we will seek to have them included in regular formal class curriculum by continuing our collaboration with teachers and administrators through our partners at Vital Link and the Orange County Department of Education.

\section{REFERENCES}

[1] Silberman, D., "Optics Outreach Evolves, OptoBotics combines optics, photonics, and robotics to engage high-school students.” in SPIE Professional Magazine, July 2013 (SPIE, Bellingham, WA 2010)

[2] Amrita Prasad ; Nathalie Debaes ; Nina Cords ; Robert Fischer ; Johan Vlekken, et al, "Photonics Explorer: revolutionizing photonics in the classroom ", Proc. SPIE8481, Optics Education and Outreach II, 84810H (October 15, 2012)

\section{FOOTNOTES}

[A] Some post paper teacher feedback was submitted and is summarized here. One teacher reported that she was unable to incorporate the Photonics Explorer Kit materials into her courses this year due to competing requirements and priorities. Another reported he was able to use the lasers for teaching about refractive index, total internal reflection and critical angle and also used the diffraction gratings and lasers in a lab on diffraction and were able to have the students determine the laser wavelength. He also used the fiber optic to discuss and demonstrate Total Internal Reflection. He also reported that the two biggest challenges were that 1) the number of students in his classes were $35-40$ and the kit was only designed for $\sim 25$. And 2) the Next Generation Science Standards (NGSS) have very little room for optics and photonics. Although when students take Advanced Placement (AP) Physics, there will be space for optics; but the number of students taking AP Physics is very small compared to those taking other science courses. 